\title{
Asymptomatic-anaplasmosis confirmation using genetic and serological tests and possible coinfection with spotted fever group Rickettsia: a case report
}

\author{
Jiyeon $\mathrm{Yoo}^{1 \dagger}$, Jong-Hoon Chung ${ }^{2 \dagger}$, Choon-Mee Kim ${ }^{3}$, Na Ra Yun ${ }^{2}$ and Dong-Min Kim² ${ }^{2^{*}}$ (I)
}

\begin{abstract}
Background: Anaplasmosis is an emerging acute febrile disease that is caused by a bite of an Anaplasma phagocytophilum-infected hard tick. As for healthy patients, reports on asymptomatic anaplasmosis resulting from such tick bites are rare.

Case presentation: A 55-year-old female patient visited the hospital with a tick bite in the right infraclavicular region. The tick was suspected to have been on the patient for more than 10 days. PCR and an indirect immunofluorescence assay (IFA) were performed to identify tick-borne infectious diseases. The blood sample collected at admission yielded a positive result in nested PCR targeting Ehrlichia- or Anaplasma-specific genes groEL and ankA. Subsequent sequencing confirmed the presence of $A$. phagocytophilum, and seroconversion was confirmed by the IFA involving an A. phagocytophilum antigen slide. PCR detected no Rickettsia-specific genes [outer membrane protein A (ompA) or surface cell antigen 1 (sca1)], but seroconversion of spotted fever group (SFG) rickettsiosis was confirmed by an IFA.

Conclusions: This study genetically and serologically confirmed an asymptomatic A. phagocytophilum infection. Although SFG rickettsiosis was not detected genetically, it was detected serologically. These findings indicate the possibility of an asymptomatic coinfection: anaplasmosis plus SFG rickettsiosis. It is, therefore, crucial for clinicians to be aware of potential asymptomatic anaplasmosis following a tick bite.
\end{abstract}

Keywords: Anaplasmosis, Anaplasma phagocytophilum, Spotted fever group rickettsiosis, Tick bites

\section{Background}

Anaplasmosis is an infection that is caused by a bite of an Anaplasma phagocytophilum-infected hard tick. It is an acute febrile disease that is characterized by a high fever after a latency period of 7-10 days [1]. The clinical manifestations of this disease can include an array of nonspecific symptoms including a fever, chills, headache,

\footnotetext{
* Correspondence: drongkim@chosun.ac.kr

†jiyeon Yoo and Jong-Hoon Chung contributed equally to this work.

2Departments of Internal Medicine, College of Medicine, Chosun University,

588 Seosuk-dong, Dong-gu, Gwangju 61453, Republic of Korea

Full list of author information is available at the end of the article
}

and muscle ache as well as possible additional symptoms such as vertigo, upper gastrointestinal tract bleeding, and seizures [2].

Anaplasmosis is an infectious disease that has become increasingly prevalent in Korea since the first reported case in 2014 [3]. Spotted fever group (SFG) rickettsiosis features signs and symptoms such as a high fever, flulike symptoms, eschar around the bite, papules, and rashes. It may also affect other organs such as the nervous system [4].

C C The Author(s). 2020 Open Access This article is licensed under a Creative Commons Attribution 4.0 International License, which permits use, sharing, adaptation, distribution and reproduction in any medium or format, as long as you give appropriate credit to the original author(s) and the source, provide a link to the Creative Commons licence, and indicate if changes were made. The images or other third party material in this article are included in the article's Creative Commons licence, unless indicated otherwise in a credit line to the material. If material is not included in the article's Creative Commons licence and your intended use is not permitted by statutory regulation or exceeds the permitted use, you will need to obtain permission directly from the copyright holder. To view a copy of this licence, visit http://creativecommons.org/licenses/by/4.0/. The Creative Commons Public Domain Dedication waiver (http://creativecommons.org/publicdomain/zero/1.0/) applies to the data made available in this article, unless otherwise stated in a credit line to the data. 
There have been cases of asymptomatic anaplasmosis in animals that have required genetic diagnosis (camels and horses) $[5,6]$ or genetic and serological diagnosis (dogs and sheep) [7, 8]. Nevertheless, human cases of asymptomatic anaplasmosis are rare [9].

In this study, we tested for asymptomatic anaplasmosis after a tick bite and a suspected coinfection with SFG Rickettsia in an otherwise healthy patient.

\section{Case presentation \\ Case}

A 55-year-old female patient visited a local clinic with a tick bite. She had no symptoms such as a headache, fever, nausea, or vomiting, but she had visited the local dermatology clinic on the day before our hospital visit to have the tick removed. She had been prescribed minocycline at the local clinic and had taken one dose in the evening before and one in the morning on the day of the visit to our hospital. She came to the Chosun University Hospital, Korea, outpatient clinic on June 19, 2018, for a second opinion. The patient was not sure of when she had been bitten by the tick. On the basis of her statement, that she had worked in fields $10-15$ days before the hospital visit, we suspected that the tick had been on her for $\sim 10$ days. During the physical examination, we found a tick bite site on the lower part of her right clavicle. Although the tick was disposed of after it was removed, she brought a picture of the tick after the removal (Fig. 1).
Although we could not accurately classify the tick morphologically or genetically, it was highly likely a nymph of either Amblyomma spp. or Haemaphysalis spp., which are common in Korea. All the laboratory test results were within reference ranges: the first blood test results revealed a white blood cell (WBC) count of $5.1 \times 10^{3} / \mu \mathrm{L}$, hemoglobin of $13.8 \mathrm{~g} / \mathrm{dL}$, and a platelet count of $2.47 \times$ $10^{5} / \mu \mathrm{L}$; the blood biochemical test results showed aspartate aminotransferase (AST) at $17.9 \mathrm{U} / \mathrm{L}$, alanine aminotransferase (ALT) at $17.1 \mathrm{U} / \mathrm{L}, \gamma$-glutamyltransferase at 21 $\mathrm{U} / \mathrm{L}$, total bilirubin at $0.48 \mathrm{mg} / \mathrm{dL}$, alkaline phosphatase (ALP) at $56 \mathrm{U} / \mathrm{L}$, glucose of $86 \mathrm{mg} / \mathrm{dL}$, blood urea nitrogen of $13.3 \mathrm{mg} / \mathrm{dL}$, creatinine at $0.66 \mathrm{mg} / \mathrm{dL}$, cholesterol at $211 \mathrm{mg} / \mathrm{dL}$, and triglycerides at $98 \mathrm{mg} / \mathrm{dL}$.

Although the patient was asymptomatic, we tested for tick-borne infectious diseases, e.g., anaplasmosis and rickettsiosis, by nested PCR (nPCR) and serological assays.

\section{nPCR}

After extracting genomic DNA from the patient's blood sample using the QIAamp Tissue and Blood Mini Kit (Qiagen, Hilden, Germany), nPCR was conducted using Ehrlichia- or Anaplasma-specific primers: the primer pairs GRO607F/GRO1294R and GRO677F/GRO1121R [10], which target the groEL (heat shock protein chaperone) gene; primer pairs ANK-F1/ANK-R1 and ANK-F2/ANK-R2 [11], which target the ankA (ankyrinrepeat protein) gene; and primer pairs AE1-F/AE1-R and

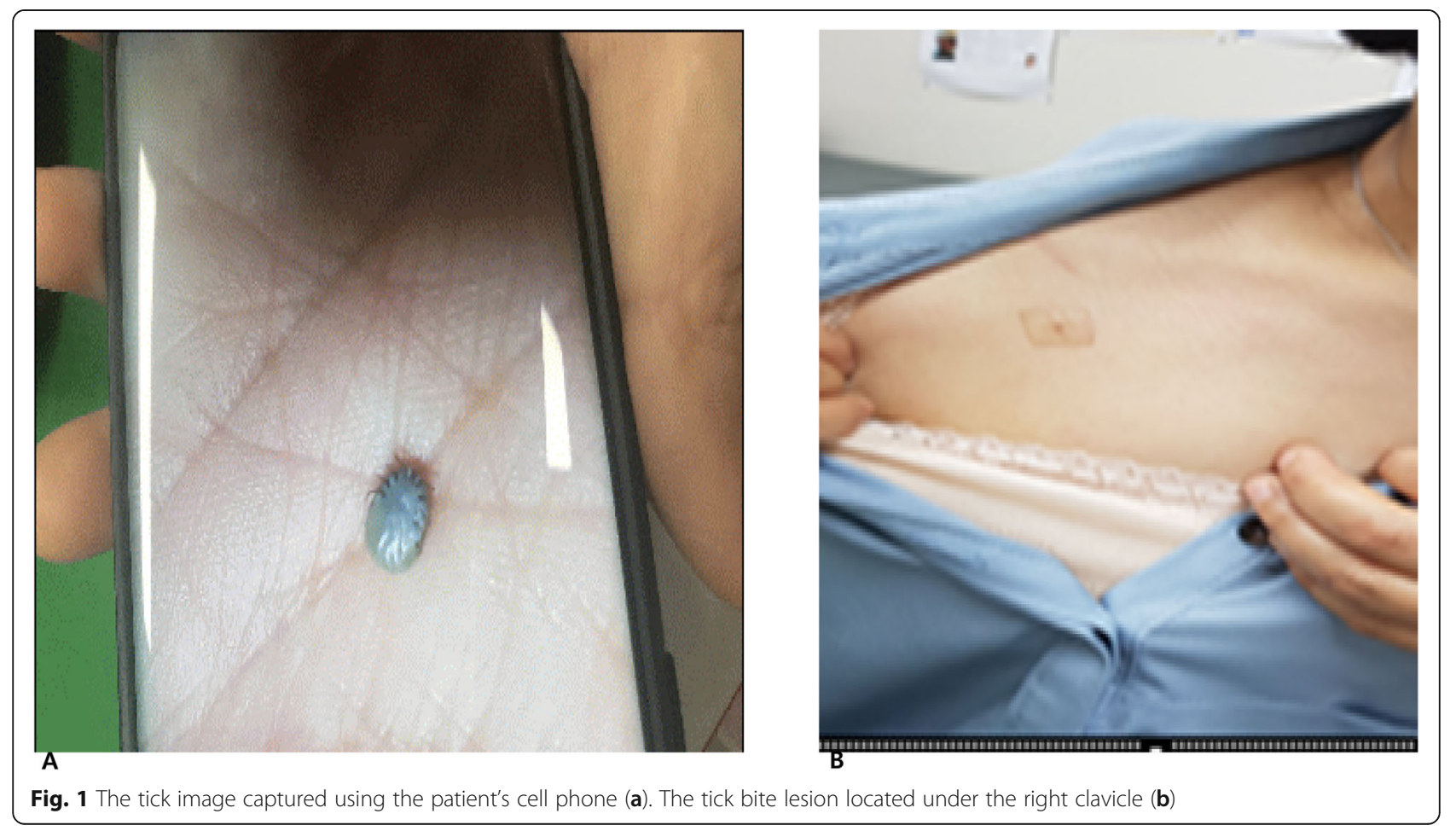


AP-F/AP-R, which target the $16 \mathrm{~S}$ ribosomal RNA (rRNA) gene [12].

To detect SFG rickettsiosis, nPCR was carried out using primer pairs sca1-6545F/sca1-7360R and sca1$6647 \mathrm{~F} / \mathrm{sca1}-7354 \mathrm{R}$, which target the sca1 (rickettsial surface protein) gene, and primers RR190.70F, RR190.602R, and RR190.701R [13], which are specific to the ompA gene. All primers that target the scal gene were designed after sequence alignment to amplify this genomic region of all Rickettsia spp. The PCR products were separated by electrophoresis on a $1.2 \%$ agarose gel. In each PCR run, the reaction mixture without the template DNA served as a negative control. The genomic DNAs of A. phagocytophilum $\mathrm{KZ} \_\mathrm{A} 3$ and Rickettsia conorii were employed as positive controls for Anaplasma-specific and SFG Rickettsia-specific targets, respectively. The details of the experimental conditions are presented in Table 1.

\section{Serological testing}

An indirect immunofluorescence assay (IFA) was performed for the serological diagnosis of the patient. To detect antibodies to SFG Rickettsia, we utilized antigen slides of $R$. conorii, $R$. japonica, and $R$. montanensis. To perform the IFA, $20 \mu \mathrm{L}$ of two-fold serial dilutions from 1:16 of the patient's serum was reacted with each rickettsial antigen slide in a humidified chamber at $37^{\circ} \mathrm{C}$ for
$30 \mathrm{~min}$. The antigen slides were washed three times with PBS and then another three times with distilled water and were air-dried. Next, the slides were incubated with $20 \mu \mathrm{L}$ of a 400-fold-diluted secondary antibody (a fluorescein isothiocyanate [FITC]-conjugated anti-human IgG or IgM antibody), washed, and air-dried in the same manner as mentioned above. The slides fixed with a mounting medium were visualized under a fluorescence microscope (U-LH100HG, Olympus Corp., Tokyo, Japan) to detect SFG Rickettsia-specific fluorescence.

To diagnose anaplasmosis, an IFA was performed in a similar manner on an antigen slide containing an $A$. phagocytophilum strain. A four-fold or greater increase in the antibody titer in the acute-phase and convalescentphase serum samples was assumed to be a positive indicator of SFG rickettsiosis and anaplasmosis [1].

The nPCR that was performed on the patient's first visit (June 19) yielded a positive result on the Ehrlichiaor Anaplasma-specific groEL and ankA genes; however, the nPCR targeting the 16S rRNA gene gave a negative result. DNA sequencing of the positive-result PCR products from the patient showed that the groEL gene sequence was a $100 \%$ match (332 out of $332 \mathrm{bp}$ ) for $A$. phagocytophilum isolates "S-DD-21," "D-SE-63," "D-GB39," and "lp11-2" (GenBank accession numbers KU519285, KU519286, KU519287, and JQ622144, respectively). Genotype S-DD-21, D-SE-63, and D-GB-39

Table 1 Nested PCR (nPCR) conditions as well as oligonucleotide primers used in this study

\begin{tabular}{|c|c|c|}
\hline Target gene ${ }^{\mathbf{a}}$ & Primer name (sequences; $5^{\prime} \rightarrow 3^{\prime}$ ) & $\begin{array}{l}\text { Amplicon size } \\
\text { (bp) }\end{array}$ \\
\hline $\begin{array}{l}\text { groEL nPCR for Anaplasmataceae } \\
\text { (external primers) }\end{array}$ & $\begin{array}{l}\text { GRO607F (GAAGATGCWGTWGGWTGTACKGC) } \\
\text { GRO1294R (AGMGCTTCWCCTTCWACRTCYTC) }\end{array}$ & 539 \\
\hline $\begin{array}{l}\text { groEL nPCR for Anaplasmataceae } \\
\text { (internal primers) }\end{array}$ & $\begin{array}{l}\text { GRO677F (ATTACTCAGAGTGCTTCTCARTG) } \\
\text { GRO1121R (TGCATACCRTCAGTYTIITCAAC) }\end{array}$ & 450 \\
\hline $16 \mathrm{~S}$ rRNA nPCR for Anaplasma and Ehrlichia species (external primers) & $\begin{array}{l}\text { AE1-F (AAGCTTAACACATGCAAGTCGAA) } \\
\text { AE1-R (AGTCACTGA CCCAACCTTAAATG) }\end{array}$ & 1406 \\
\hline $\begin{array}{l}16 \mathrm{~S} \text { rRNA nPCR for } \\
\text { A. phagocytophilum } \\
\text { (internal primers) }\end{array}$ & $\begin{array}{l}\text { AP-F (GTCGAACGGATTATTCTTATAAGCTTGC) } \\
\text { AP-R (CCCTTCCGTTAAGAAGGATCTAATCTCC) }\end{array}$ & 926 \\
\hline $\begin{array}{l}\text { ankA nPCR for } \\
\text { A. phagocytophilum } \\
\text { (external primers) }\end{array}$ & $\begin{array}{l}\text { ANK-F1 (GAAGAAATTACAACTCCTGAAG) } \\
\text { ANK-R1 (CAGCCAGATGCAGTAACGTG) }\end{array}$ & 705 \\
\hline $\begin{array}{l}\text { ankA nPCR for } \\
\text { A. phagocytophilum } \\
\text { (internal primers) }\end{array}$ & $\begin{array}{l}\text { ANK-F2 (TTGACCGCTGAAGCACTAAC) } \\
\text { ANK-R2 (ACCATTTGCTTCTTGAGGAG) }\end{array}$ & 664 \\
\hline $\begin{array}{l}\text { sca1 nPCR for SFG } \\
\text { Rickettsia (external primers) }\end{array}$ & $\begin{array}{l}\text { sca1-6545F (ATTCGTAACAGATTAGATRC) } \\
\text { sca1-7360R (TTATAGGATGTTTCGGTTG) }\end{array}$ & 815 \\
\hline sca1 nPCR for SFG Rickettsia (internal primers) & $\begin{array}{l}\text { sca1-6647F (TGGATGCGTGSTATGTACG) } \\
\text { sca1-7354R (GATGTTTTCGGTTGYTTCGG) }\end{array}$ & 707 \\
\hline ompA nPCR for SFG Rickettsia (external primers) & $\begin{array}{l}\text { R190.70F (ATGGCGAATATTCTCCAAAAA) } \\
\text { RR190.701R (GTTCCGTAATGGCAGCATCT) }\end{array}$ & 634 \\
\hline ompA nPCR for SFG Rickettsia (internal primers) & $\begin{array}{l}\text { R190.70F (ATGGCGAATATTTCTCCAAAAA) } \\
\text { RR190.602R (AGTGCAGCATTCGCTCCCCCT) }\end{array}$ & 535 \\
\hline
\end{tabular}

a ankA ankyrin-repeat protein gene, groEL heat shock protein chaperone gene, $r R N A$ ribosomal RNA, sca1 surface cell antigen 1 (rickettsial surface protein) gene, ompA outer membrane protein A gene 
were originally identified in Korean cats and dogs, and isolate lp11-2 originates from a Japanese tick. Isolate gw1, which was originally collected from a Korean patient, had the second-highest homology with our strain, and phylogenetic-tree analysis showed that our strain belongs to the same group as A. phagocytophilum (Fig. 2a). The ankA gene sequence from the microbe(s) found in our patient was $99.8 \%$ (558/559 bp) homologous to that of $A$. phagocytophilum isolates gw1 and KZA1 (accession numbers KJ677106 and KT986059, respectively), which were originally collected from a Korean patient. Moreover, the phylogenetic-tree analysis confirmed that the ankA sequence places our microbial isolate into the same group as A. phagocytophilum (Fig. $2 \mathrm{~b})$. DNA sequence analysis and the phylogenetic tree based on the groEL and ankA sequences confirmed the presence of $A$. phagocytophilum in the patient, despite the lack of symptoms. By contrast, in the PCR assay, the same blood sample collected during the patient's hospital visit tested negative for Rickettsia-specific ompA and sca1.

To isolate the bacterial strain, we performed an animal experiment. The patient's blood was intraperitoneally injected into a BALB/c mouse obtain from ORIENT BIO (Seongnam-si, Gyeonggi-do, Korea), treated with cyclophosphamide (Sigma-Aldrich, St. Louis, MO, USA). The mouse was euthanized by inhalation of $5 \%$ isoflurane and then dissected, subsequent nPCR performed on the mouse's spleen, kidney, and liver yielded a negative result on the Rickettsia-specific scal gene and Anaplasma-specific genes groEL and ankA.

The IFA for antibodies to an A. phagocytophilum antigen on June 19th (first visit) gave a negative result on both IgG and IgM (Table 2). By contrast, the IFA for an anti-A. phagocytophilum antibody performed on June 22nd (second visit) yielded an IgG-negative but IgMpositive result (1:16). On June 28th (third visit), seroconversion was confirmed because the serum sample was IgG negative and IgM positive (1:32). The anti- $R$. conorii antibody IFA performed on June 28th showed an elevated (to 1:64) IgG titer [14].

\section{Discussion and conclusion}

Ticks in the Ixodidae family can serve as vectors of $A$. phagocytophilum and SFG Rickettsia. They usually live in tropical regions as well as in South Asia, Japan, and Korea. In Korea, they are known to be found, for example, on Jeju Island, in Suncheon (South Jeolla Province), Tongyoung, and Changwon (Gyeongsang Province). The first case of a tick bite in Korea was reported in Damyang-gun, South Jeolla Province [15]. Previous reports indicate that larvae require 3 to 5 days to have a meal of their hosts' blood. After the metamorphosis of the larvae, a nymph requires 7 to 10 days to transform into an imago; before shedding, an imago requires feeding on its respective host's blood for 6 to 13 days. Unlike Borrelia burgdorferi, A. phagocytophilum and SFG Rickettsia get inoculated into a host within 2 to $6 \mathrm{~h}$ of attachment following a tick bite [16].

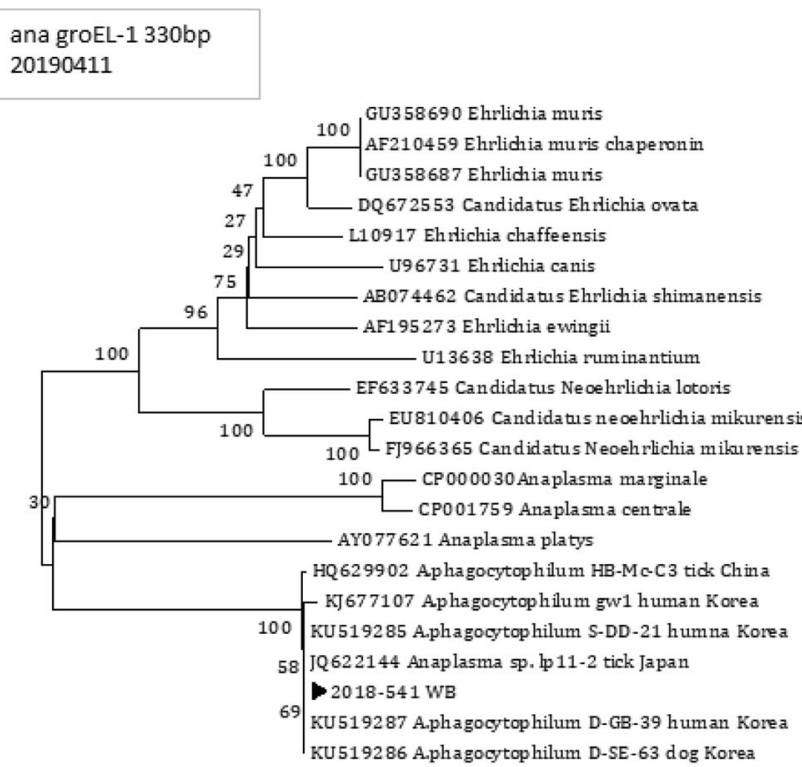

$\longmapsto .02$

A

\section{ana anka $564 \mathrm{bp}$}

20190411

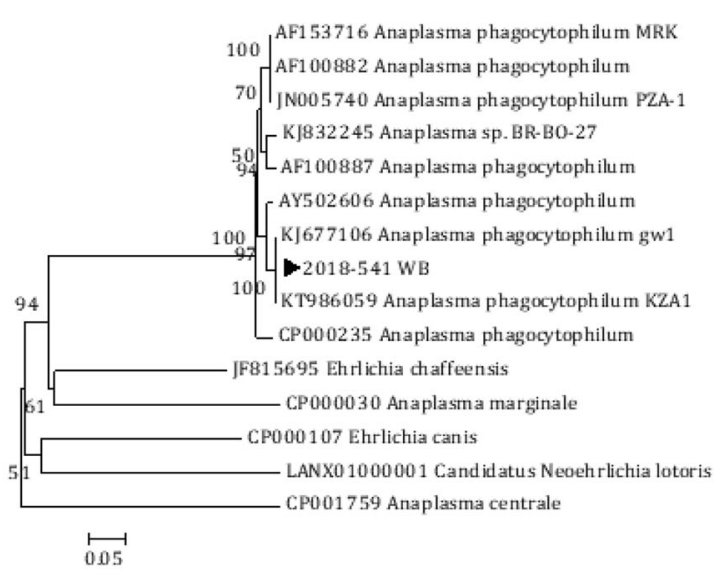

Fig. 2 Phylogenetic-tree positions of the A. phagocytophilum-specific groEL and ankA sequences in the patient. The arrowhead indicates our strain 
Table 2 Nested PCR (nPCR) and indirect immunofluorescence assay (IFA) results for anaplasmosis and rickettsiosis

\begin{tabular}{|c|c|c|c|c|c|c|c|c|c|c|}
\hline \multirow[t]{3}{*}{ Date } & \multicolumn{3}{|l|}{ Anaplasmosis } & \multicolumn{7}{|c|}{ Rickettsiosis } \\
\hline & \multirow[t]{2}{*}{$\mathrm{nPCR}$} & \multicolumn{2}{|l|}{ IFA } & \multirow[t]{2}{*}{$\mathrm{nPCR}$} & \multicolumn{2}{|c|}{$\begin{array}{l}\text { IFA } \\
\text { (R. conorii) }\end{array}$} & \multicolumn{2}{|c|}{$\begin{array}{l}\text { IFA } \\
\text { (R. japonica) }\end{array}$} & \multicolumn{2}{|c|}{$\begin{array}{l}\text { IFA } \\
\text { (R. montanensis })\end{array}$} \\
\hline & & $\lg G$ & $\lg M$ & & $\lg G$ & $\lg \mathrm{M}$ & $\lg G$ & $\lg M$ & $\lg G$ & $\lg M$ \\
\hline 19 June & $\begin{array}{l}\underset{(-)}{\operatorname{groEL}}(+) \text { ankA }(+) 16 \mathrm{~S} \text { rRNA } \\
\end{array}$ & $<1: 16$ & $<1: 16$ & $\begin{array}{l}\operatorname{scal}(-) \\
\operatorname{ompA}(-)\end{array}$ & $<1: 16$ & 1:256 & 1:128 & $<1: 16$ & $1: 32$ & $<1: 16$ \\
\hline 22 June & & $<1: 16$ & $1: 16$ & scal (-) & $<1: 16$ & $1: 512$ & $1: 128$ & $<1: 16$ & $1: 32$ & $<1: 16$ \\
\hline 28 June & $\begin{array}{l}\operatorname{groEL}(-) \\
\operatorname{ank} A(-)\end{array}$ & $<1: 16$ & $1: 32$ & $\operatorname{scal}(-)$ & $1: 64$ & $1: 256$ & $1: 64$ & $<1: 16$ & $1: 32$ & $<1: 16$ \\
\hline
\end{tabular}

$n P C R$ nested $P C R$, IFA indirect immunofluorescence assay

The serological diagnosis of an $A$. phagocytophilum infection can be confirmed when there is a four-fold increase in the antibody titer in convalescent-phase serum compared to that in acute-phase serum $[17,18]$. Because the increase in the plasma concentration of antibodies in response to $A$. phagocytophilum proceeds slowly, a significant increase is not detectable in the acute phase. Furthermore, there are cases where rescreening for antibodies should be performed at $\sim 1$ month after the original test $[18,19]$. In the anaplasmosis IFA, our patient tested negative on the first visit, but IgM seroconversion was confirmed in the follow-up tests on June 22nd and June 28th. Moreover, although the patient presented no symptoms, the nPCR results were positive for the $A$. phagocytophilum-specific genes groEL and ankA; accordingly, the patient received a diagnosis of asymptomatic $A$. phagocytophilum infection.

The anti- $R$. conorii antibody IFA performed on June 19th gave a negative result on IgG, but the IgG titer was found to have increased to a ratio of 1:64 in the IFA that was performed later, i.e., on June 28th. The IFA for antibodies to $R$. japonica and $R$. montanensis yielded positive results with low IgG titers. The sca1 nPCR gave a negative result on Rickettsia on June 19. Nonetheless, because the patient had taken two doses of minocycline (a tetracycline antibiotic) since the tick bite, it was unclear whether SFG rickettsiosis could not be detected by PCR owing to the antibiotic. Therefore, we could not rule out the possibility of SFG Rickettsia coinfection and the possibility of a cross-reaction due to the A. phagocytophilum infection [19].

Currently, there are published cases of asymptomatic anaplasmosis in various animals, including camels, horses, dogs, and sheep [19]. In contrast, there are few studies on the genetic and serological diagnosis of this infection in humans. In a study involving 148 blood samples from people with HIV infection, Welc-Falęciak et al. confirmed two cases of asymptomatic infection by tick-borne pathogens: Borrelia garinii and A. phagocytophilum [9]. There is a report of asymptomatic anaplasmosis in people with HIV infection, but no study has shown a genetic and serological diagnosis of asymptomatic anaplasmosis in non-HIV patients.

One limitation of this study is that the asymptomatic infection could not be definitively diagnosed by the culture method. We attempted to culture Anaplasma and Rickettsia by means of a mouse but failed. Additional studies in healthy adults are needed to determine whether the failure of culturing was because of minocycline administration or the low Anaplasma cell numbers in an asymptomatic infection. Seroconversion of SFG rickettsiosis was confirmed in our patient, and further studies are needed to examine whether the antibodies to SFG Rickettsia that were produced in the acute phase of anaplasmosis were a result of a cross-reaction. Furthermore, additional studies are necessary to investigate whether the absence of symptoms in our patient with anaplasmosis was a consequence of taking minocycline during the latency period.

In conclusion, in this study, we diagnosed an asymptomatic A. phagocytophilum infection both genetically and serologically. Furthermore, although SFG rickettsiosis was not confirmed genetically, seroconversion was confirmed, suggesting a possible coinfection with SFG Rickettsia. Therefore, clinicians should be aware of the possibility of asymptomatic anaplasmosis after a tick bite.

\section{Abbreviations}

ALT: Alanine aminotransferase; ALP: Alkaline phosphatase; AnkA: Ankyrinrepeat protein; AST: Aspartate aminotransferase; GroEL: Heat shock protein chaperone; IFA: Indirect immunofluorescence assay; nPCR: Nested PCR; OmpA: Outer membrane protein A; Sca1: Rickettsial surface protein, surface cell antigen 1; SFG: Spotted fever group; WBC: White blood cell

\section{Acknowledgments}

For a thorough review of this manuscript, we would like to thank Park Jungseo, Mun Bomi, Shim Jongbo, Jung Jungtae, Noh Jinhee, Hwang Inyoung, and Kim Su A.

\section{Authors' contributions}

DMK: designed and coordinated the study and contributed to drafting and reviewing the manuscript. YJ and JHC: collected the patient's clinical data, wrote the manuscript, and revised the draft during the submission. CMK: carried out the molecular analysis and serological testing, wrote the manuscript, and also revised the draft during the submission. NRY: was directly responsible for the patient's care, performed the clinical 
examinations, and helped draft the manuscript. All the authors read and approved the final version of the manuscript.

\section{Availability of data and materials}

The datasets analysed during the current study are available at National Center for Biotechnology Information (NCBI) repository, (accession numbers; KU519285, KU519286, KU519287, JQ622144, KJ677106 and KT986059).

\section{Ethics approval and consent to participate}

The study protocol was approved by the Ethics in Human Research Committee of Chosun University Hospital (IRB decisions No. 2013-10-001018 and 2016-07-014-009). The adult human subject provided written informed consent to participate in the study. Animal experiment was performed in accordance with an approved animal use protocol from Chosun University Institutional Animal Care and Use Committee (CIACUC) under approval number CIACUC2017-S0026.

\section{Consent for publication}

Written informed consent was obtained from the patient for publication of this case report and any accompanying images.

\section{Competing interests}

The authors declare that they have no competing interests.

\section{Author details}

${ }^{1}$ College of Medicine, Chosun University, Gwangju, South Korea.

${ }^{2}$ Departments of Internal Medicine, College of Medicine, Chosun University, 588 Seosuk-dong, Dong-gu, Gwangju 61453, Republic of Korea. ${ }^{3}$ Premedical Science, College of Medicine, Chosun University, Gwangju, Republic of Korea.

Received: 7 January 2020 Accepted: 17 June 2020

Published online: 30 June 2020

\section{References}

1. Kim SW, Kim CM, Kim DM, Yun NR. Manifestation of anaplasmosis as cerebral infarction: a case report. BMC Infect Dis. 2018;18(1):409.

2. Bakken JS, Krueth J, Wilson-Nordskog C, Tilden RL, Asanovich K, Dumler JS. Clinical and laboratory characteristics of human granulocytic ehrlichiosis. JAMA. 1996;275(3):199-205.

3. Kim KH, Yi J, Oh WS, Kim NH, Choi SJ, Choe PG, et al. Human granulocytic anaplasmosis, South Korea, 2013. Emerg Infect Dis. 2014;20(10):1708-11.

4. Solano-Gallego L, Capri A, Pennisi MG, Caldin M, Furlanello T, Trotta M. Acute febrile illness is associated with rickettsia spp infection in dogs. Parasit Vectors. 2015:8:216.

5. Bahrami S, Hamidinejat H, Tafreshi ARG. First molecular detection of Anaplasma Phagocytophilum in dromedaries ( Camelus Dromedarius). J Zoo Wildl Med. 2018;49(4):844-8.

6. Praskova I, Bezdekova B, Zeman P, Jahn P. Seroprevalence of Anaplasma phagocytophilum in horses in the Czech Republic. Ticks Tick Borne Dis. 2011;2(2):111.

7. Carrade DD, Foley JE, Borjesson DL, Sykes JE. Canine granulocytic anaplasmosis: a review. J Vet Intern Med. 2009;23(6):1129-41.

8. Gorman JK, Hoar BR, Nieto NC, Foley JE. Evaluation of Anaplasma phagocytophilum infection in experimentally inoculated sheep and determination of Anaplasma spp seroprevalence in 8 free-ranging sheep flocks in California and Oregon. Am J Vet Res. 2012;73(7):1029-34.

9. Welc-Faleciak R, Kowalska JD, Bednarska M, Szatan M, Pawelczyk A. Molecular identification of tick-borne pathogens in asymptomatic individuals with human immunodeficiency virus type 1 (HIV-1) infection: a retrospective study. BMC Infect Dis. 2018;18(1):227.

10. Pritt BS, Sloan LM, Johnson DK, Munderloh UG, Paskewitz SM, McElroy KM, et al. Emergence of a new pathogenic Ehrlichia species, Wisconsin and Minnesota, 2009. N Engl J Med. 2011;365(5):422-9.

11. Massung RF, Levin ML, Munderloh UG, Silverman DJ, Lynch MJ, Gaywee JK, et al. Isolation and propagation of the Ap-variant 1 strain of Anaplasma phagocytophilum in a tick cell line. J Clin Microbiol. 2007:45(7):2138-43.

12. Kim CM, Yi YH, Yu DH, Lee MJ, Cho MR, Desai AR, et al. Tick-borne rickettsial pathogens in ticks and small mammals in Korea. Appl Environ Microbiol. 2006;72(9):5766-76.

13. Eremeeva ME, Bosserman EA, Demma $\sqcup$, Zambrano ML, Blau DM, Dasch GA. Isolation and identification of rickettsia massiliae from Rhipicephalus sanguineus ticks collected in Arizona. Appl Environ Microbiol. 2006;72(8): 5569-77.

14. Park SW, Lee CS, Kim JH, Bae IG, Moon C, Kwak YG, et al. Severe fever with thrombocytopenia syndrome: comparison with scrub typhus and clinical diagnostic prediction. BMC Infect Dis. 2019;19(1):174.

15. Kim YH, Lee JH, Park YM, Lee JY. Tick Bite by Nymphal Amblyomma testudinarium. Ann Dermatol. 2016;28(6):762-4.

16. Katavolos P, Armstrong PM, Dawson JE, Telford SR. 3rd: Duration of tick attachment required for transmission of granulocytic ehrlichiosis. J Infect Dis. 1998;177(5):1422.

17. Kim CM, Kim SW, Kim DM, Yoon NR, Jha P, Jang SJ, et al. Case report: polymerase chain reaction testing of tick bite site samples for the diagnosis of human granulocytic Anaplasmosis. Am J Trop Med Hyg. 2017;97(2):403-6.

18. Wass L, Grankvist A, Mattsson M, Gustafsson H, Krogfelt K, Olsen B, et al. Serological reactivity to Anaplasma phagocytophilum in neoehrlichiosis patients. Eur J Clin Microbiol Infect Dis. 2018;37(9):1673-8.

19. Bakken JS, Dumler JS. Human granulocytic anaplasmosis. Infect Dis Clin N Am. 2015;29(2):341-55.

\section{Publisher's Note}

Springer Nature remains neutral with regard to jurisdictional claims in published maps and institutional affiliations.

\section{Ready to submit your research? Choose BMC and benefit from:}

- fast, convenient online submission

- thorough peer review by experienced researchers in your field

- rapid publication on acceptance

- support for research data, including large and complex data types

- gold Open Access which fosters wider collaboration and increased citations

- maximum visibility for your research: over $100 \mathrm{M}$ website views per year

At BMC, research is always in progress.

Learn more biomedcentral.com/submission 